\title{
Comment on 'Cefiderocol, a New Siderophore Cephalosporin for the Treatment of Complicated Urinary Tract Infections Caused by Multidrug-resistant Pathogens: Preclinical and Clinical Pharmacokinetics, Pharmacodynamics, Efficacy and Safety'
}

\author{
Andrew Koren ${ }^{1}$ (D) $\cdot$ Andreas Karas $^{2} \cdot$ Roger Echols $^{3}$
}

Accepted: 27 April 2021 / Published online: 26 May 2021

(c) The Author(s) 2021

\section{Dear Editors,}

We read with interest the paper by Lee et al., which reviewed the in vitro, in vivo, and clinical data on cefiderocol [1]. However, we would like to address and highlight for your readers, the inaccurate characterization of all-cause mortality (ACM) in the APEKS-NP (NCT03032380, EudraCT 2016-003020-23) clinical trial and the subsequent conclusion drawn from this mischaracterization.

APEKS-NP was specifically designed to assess mortality in the nosocomial pneumonia patient population. Furthermore, APEKS-NP met its primary endpoint of noninferiority. ACM in the cefiderocol arm was $12.4 \%$ versus $11.6 \%$ in the high-dose meropenem arm with a treatment difference of $0.8 \%$ [ $95 \% \mathrm{CI}-6.6$ to 8.2 ] demonstrating that cefiderocol was non-inferior to high-dose meropenem in critically ill patients with nosocomial pneumonia caused by a broad range of Gram-negative bacteria, including Acinetobacter baumannii, Pseudomonas aeruginosa, and Enterobacteriaceae [2, 3]. APEKS-NP subsequently served as the basis of approval by the US Food and Drug Administration (FDA) for use of cefiderocol in hospital-acquired

This comment refers to the article available online at https://doi. org/10.1007/s40261-020-00955-x.

Andrew Koren

Andrew.Koren@shionogi.com

Andreas Karas

Andreas.Karas@shionogi.eu

Roger Echols

REchols@shionogi.com

1 Shionogi Inc, Florham Park, NJ, USA

2 Shionogi Europe, London, UK

3 ID3C, Easton, CT, USA and ventilator-acquired pneumonias (HAP/VAP) due to susceptible Gram-negative microorganisms, and supported removal of the restriction of limited or no alternative treatment options, and limited safety and efficacy data statements from the cefiderocol label [4].

From these results, Lee et al. draw the conclusion that cefiderocol should be limited only to the treatment of cUTIs from Gram-negative bacteria [1]. Our organization, as well as the FDA and European Medicines Agency, examined these results and concluded that cefiderocol can be used in patients with cUTI and HAP/VAP as evidenced by cefiderocol's current FDA-approved indication as well as the pathogen-focused indication in the European Union [4, 5].

Thank you for the opportunity to respond to Lee et al. We hope this letter helps clarify the design, results and interpretation of APEKS-NP and cefiderocol's place in therapy.

\section{Declarations}

Funding No funding was received to prepare this letter.

Conflict of interest Andrew Koren and Andreas Karas are employees of Shionogi Inc. Roger Echols is a consultant for Shionogi and received a consultancy fee for his services.

Open Access This article is licensed under a Creative Commons Attribution-NonCommercial 4.0 International License, which permits any non-commercial use, sharing, adaptation, distribution and reproduction in any medium or format, as long as you give appropriate credit to the original author(s) and the source, provide a link to the Creative Commons licence, and indicate if changes were made. The images or other third party material in this article are included in the article's Creative Commons licence, unless indicated otherwise in a credit line to the material. If material is not included in the article's Creative Commons licence and your intended use is not permitted by statutory regulation or exceeds the permitted use, you will need to obtain permission 
directly from the copyright holder. To view a copy of this licence, visit http://creativecommons.org/licenses/by-nc/4.0/.

\section{References}

1. Lee YR, Yeo S. Cefiderocol, a new siderophore cephalosporin for the treatment of complicated urinary tract infections caused by multidrug-resistant pathogens: preclinical and clinical pharmacokinetics, pharmacodynamics, efficacy and safety. Clin Drug Investig. 2020;40:901-13. https://doi.org/10.1007/ s40261-020-00955-x.
2. Wunderink RG, Matsunaga Y, Ariyasu M, Clevenbergh P, Echols $\mathrm{R}$, Kaye KS, et al. Cefiderocol versus high-dose, extended-infusion meropenem for the treatment of Gram-negative nosocomial pneumonia (APEKS-NP): a randomised, double-blind, phase 3, non-inferiority trial. Lancet Infect Dis. October 2020 (online).

3. FDA Antimicrobial Drugs Advisory Committee, Cefiderocol Briefing Document NDA \#209445. Shionogi Inc. https://www. fda.gov/media/131705/download. Accessed 27 May 2020.

4. Fetroja ${ }^{\circledR}$ Prescribing Information: Drugs@ $@$ FA, Reference ID: 4676517. revised 20 September 2020

5. European Medicines Agency. Fetcroja (cefiderocol) EPAR. Available at: https://www.ema.europa.eu/en/medicines/human/EPAR/ fetcroja\#product-information-section. Accessed 9 Mar 2021. 